University of South Florida

DIGITAL COMMONS

Digital Commons @ University of

@ UNIVERSITY OF SOUTH FLORIDA

South Florida

\title{
Long-period Ocean Heat Storage Rates and Basin-scale Heat Fluxes from TOPEX
}

D. P. Chambers

University of Texas at Austin, donc@usf.edu

B. D. Tapley

R. H. Stewart

Follow this and additional works at: https://digitalcommons.usf.edu/msc_facpub

Part of the Life Sciences Commons

\section{Scholar Commons Citation}

Chambers, D. P.; Tapley, B. D.; and Stewart, R. H., "Long-period Ocean Heat Storage Rates and Basin-scale Heat Fluxes from TOPEX" (1997). Marine Science Faculty Publications. 1431.

https://digitalcommons.usf.edu/msc_facpub/1431

This Article is brought to you for free and open access by the College of Marine Science at Digital Commons @ University of South Florida. It has been accepted for inclusion in Marine Science Faculty Publications by an authorized administrator of Digital Commons @ University of South Florida. For more information, please contact digitalcommons@usf.edu. 


\title{
Long-period ocean heat storage rates and basin-scale heat fluxes from TOPEX
}

\author{
D. P. Chambers and B. D. Tapley \\ Center for Space Research, University of Texas at Austin
}

\section{R. H. Stewart}

Department of Oceanography, Texas A \& M University, College Station

\begin{abstract}
Over 3 years of TOPEX altimeter data have been used to estimate annual heat storage and long-period heat storage rates in $1^{\circ}$ grids over the global oceans $\left(65^{\circ} \mathrm{S}\right.$ to $\left.65^{\circ} \mathrm{N}\right)$. The mean annual heat storage rates computed from the TOPEX data agree with those computed from monthly-mean temperatures to within $30 \mathrm{~W} \mathrm{~m}^{-2}$. The accuracy of long-term heat storage rates is estimated to be less than $10 \mathrm{~W} \mathrm{~m}^{-2}$ over mid and low latitudes. Regional heat storage rates are larger than this error in many regions, most notably in the tropical Pacific and Indian Oceans and in the northern Atlantic Ocean. The heat storage changes associated with the 1991-1993 El Niño event are evident and agree with values computed from in situ measurements collected by the Tropical Ocean-Global Atmosphere program Tropical Atmosphere Ocean array moorings. The heat storage rates inferred from TOPEX data are also shown to qualitatively agree with sea surface temperature rates computed over the same time period. Finally, heat storage rates are integrated over ocean gyres to estimate atmosphere-ocean heat fluxes. Results suggest that from 1993 to 1995 the North Atlantic and the southern hemisphere gained heat from the atmosphere at a rate of between 1.5 and $2 \mathrm{~W} \mathrm{~m}^{-2}$, while the North Pacific either lost heat or maintained zero net flux. However, the estimated error on this measurement is of the order of $1.5 \mathrm{~W} \mathrm{~m}^{-2}$ indicating the true flux could be from 0 to $3 \mathrm{~W} \mathrm{~m}^{-2}$. Both the TOPEX and temperature measurements suggest that the North Atlantic gained more heat per unit area than the North Pacific between 1992 and 1995.
\end{abstract}

\section{Introduction}

One of the principal goals of global climate research is the prediction of long-period changes in the Earth's climate. Of the many parameters which influence long-term climate changes, one of the most important and most poorly measured is the variation in heat storage in the ocean. It is well known that the ocean heat budget has a strong annual cycle [Gill and Niiler, 1973], as the ocean stores heat during the summer months and releases it over the year, with a peak loss in the late fall, early winter. The annual variability helps maintain temperate seasons, particularly in the northern hemisphere, where the air is warmed in the winter due to large heat losses from the western boundary currents. It is currently believed that subtle, long-period changes in the ocean heat storage can have significant effects on the climate, the most dramatic being a trigger for starting or stopping ice ages. Although mean annual and monthly variations of the ocean heat budget have been determined using bulk formulae and historical data from the last century [e.g., Esbensen and Kushnir, 1981], interannual variations over the global oceans have been difficult to compute because of the lack of data.

Traditionally, stored heat is computed from ocean temperature changes, such as those made by expendable bathythermographs (XBTs), by integrating temperatures through the water column to some reference level [e.g., Yan et al., 1995]:

$$
\Delta H=\rho c_{p} h \Delta T_{a}
$$

Copyright 1997 by the American Geophysical Union

Paper number $96 \mathrm{JC} 03644$

0148-0227/97/96JC-03644\$09.00

$$
T_{a}=\frac{1}{h} \int_{-h}^{0} T d z
$$

where $\Delta H$ is the stored heat anomaly per unit area, $\rho$ is the density and is assumed constant, $c_{p}$ is the specific heat of seawater and is assumed constant, $h$ is the depth to the reference level, and $\Delta T_{a}$ is the vertically averaged temperature anomaly. Although temperature data are not globally distributed, they can be used to infer regional heat storage with some accuracy. The error in the stored heat measurement is estimated to be about $15 \mathrm{x}$ $10^{7} \mathrm{~J} \mathrm{~m}^{-2}$ over an annual cycle [Wyrtki and Uhrich, 1982], which is approximately the same size as expected interannual signals. Another large uncertainty is the error in determining the reference level above which most of the heating occurs. Methods of defining the reference level vary from study to study, but it is commonly set at either a constant depth, a mean annual depth, or the depth to a particular isotherm in the thermocline. The latter is the preferred method, since there is little vertical mixing across a constant temperature surface witbin the thermocline [Stevenson and Niiler, 1983]. The errors due to the uncertainty of the reference level combined with its variability over the time domain the data are averaged over can be the same size as or larger than that of the measurement errors [Wyrtki and Uhrich, 1982]. Converted into heat storage rate, the total error from temperature measurements is estimated to be between 20 and 40 $\mathrm{W} \mathrm{m}^{-2}$ for the annual cycle [Wyrtki and Uhrich, 1982; Yan et al., 1995].

However, changes in heat storage will also cause changes in the ocean topography, since heat variations are associated with density changes [Gill and Niiler, 1973]. Using a relationship between heat storage and density change, one can envision an equation relating sea level change to heat storage directly. The main advantage to deriving heat storage from the sea level is that 
no assumption about a mixed layer depth is needed. The sea level is sensitive to changes in the heating throughout the water column and can detect heat storage changes even in the deepest layers. Sea level changes measured by tide gauges in the tropics have been shown to be very well correlated with heat content [Repert et al., 1985], but this has limited benefit because there are only a few hundred tide gauges scattered around the globe, mostly in the tropics and along continental coasts, and few are in deep waters. However, sea level variability measured by the TOPEX altimeter has been shown to have a similar accuracy to that measured by tide gauges [Cheney et al., 1994; Mitchum, 1994; Tapley et al., 1994], and the TOPEX sea levels have been shown to be well correlated with heat storage computed from XBT data over the northern hemisphere [White and Tai, 1995]. They estimate that basin-wide averages of long-term heat storage rates can be inferred from TOPEX altimetry using the coefficients relating TOPEX measured sea level to heat storage with an accuracy of about $2 \mathrm{~W} \mathrm{~m}^{-2}$.

Instead of using direct temperature measurements and deriving a linear relation between TOPEX-measured sea levels and heat storage as White and Tai [1995] have done, we want to examine the theoretical basis of the relationship and base our calculations on an equation utilizing only sea level measurements and certain constants. To first order, the temperature change in (1) will cause a change in density according to

$$
\Delta p=-p \alpha \Delta T_{a},
$$

where $\alpha$ is the thermal expansion coefficient of seawater and is strongly dependent on the temperature and pressure level of the water parcel. A change in density due to heating will cause a change in sea level, $\Delta \eta$, as

$$
\Delta p=\frac{-p \Delta \eta}{(h+\Delta \eta)} \approx \frac{-p \Delta \eta}{h},
$$

assuming that $\Delta \eta$ is much smaller than $h$. This is true, since the change in sea level is only a few centimeters, while the depth of the upper, mixed layer is of the order of tens or hundreds of meters. Therefore a temperature change can be related to a change in sea level through (3) and (4), and (1) can be rewritten as

$$
\Delta H=\frac{p c_{p}}{\alpha} \Delta \eta
$$

Thus (5) relates thermal sea level changes from the mean to heat storage anomalies via the coefficients $\alpha, \rho$, and $c_{p}$. These coefficients can be estimated from monthly-mean climatological data and an equation of state [e.g., Gill, 1982, Table A.3.1]. Even in regions where the heat storage changes are due to changes in the mixed layer depth forced by Ekman pumping, such as in the tropics, this relation should still be valid since the heating due to the change in mixed layer depth is equivalent to a temperature change over a fixed depth. More problematic in this relation, however, is the fact that $\Delta \eta$ is the change in sea level due only to heating but that the sea level measured by altimetry contains other effects, such as changes due to fluctuations in atmospheric pressure, changes due to variations in the water salinity, and changes due to the barotropic response of the ocean to wind forcing.

Although the atmospheric pressure effect can be removed to first order by assuming an inverted barometer, the sea level effects due to salinity changes and the barotropic forcing are harder to compute. However, these effects are generally smaller than the thermal effects. Seasonal changes in the surface salinity due to freshwater flux are small over most of the ocean, except near river outlets and regions of seasonal upwelling (Figure 1). The annual surface salinity amplitude is less than 0.2 parts per thousand (ppt) over most of the ocean, which means that the sea level amplitude would change by about $0.1 \mathrm{~mm}$ per meter of mixing depth (with a coefficient of contraction $=7.5 \times 10^{-4}$ ). Assuming a mixed layer depth of $100 \mathrm{~m}$, and a constant salinity change of 0.2 over this depth, the sea level amplitude would be $1.5 \mathrm{~cm}$. However, the seasonal salinity variability generally decreases with depth, since it is predominately caused by the difference between precipitation and evaporation at the surface. Gill and Niiler [1973, Figure 2] estimate that the mean annual amplitude of the steric effect due to salinity is about $3 \mathrm{~mm}$ in the North Atlantic and North Pacific. Gill and Niiler [1973, Figure 3] also estimate that the mean annual amplitude of the barotropic response to wind forcing is the same size. $F u$ and Davidson [1995] have shown that the barotropic effect on sea level is large compared to the other sea level components only in the extreme northeastern and southeastern Pacific.

Thus, after correcting for the inverted barometer effect, the sea level change due to heating can be approximated from the sea level anomaly measured by the TOPEX altimeter as

$$
\Delta \eta=\Delta \eta^{T O P E X}+\varepsilon,
$$

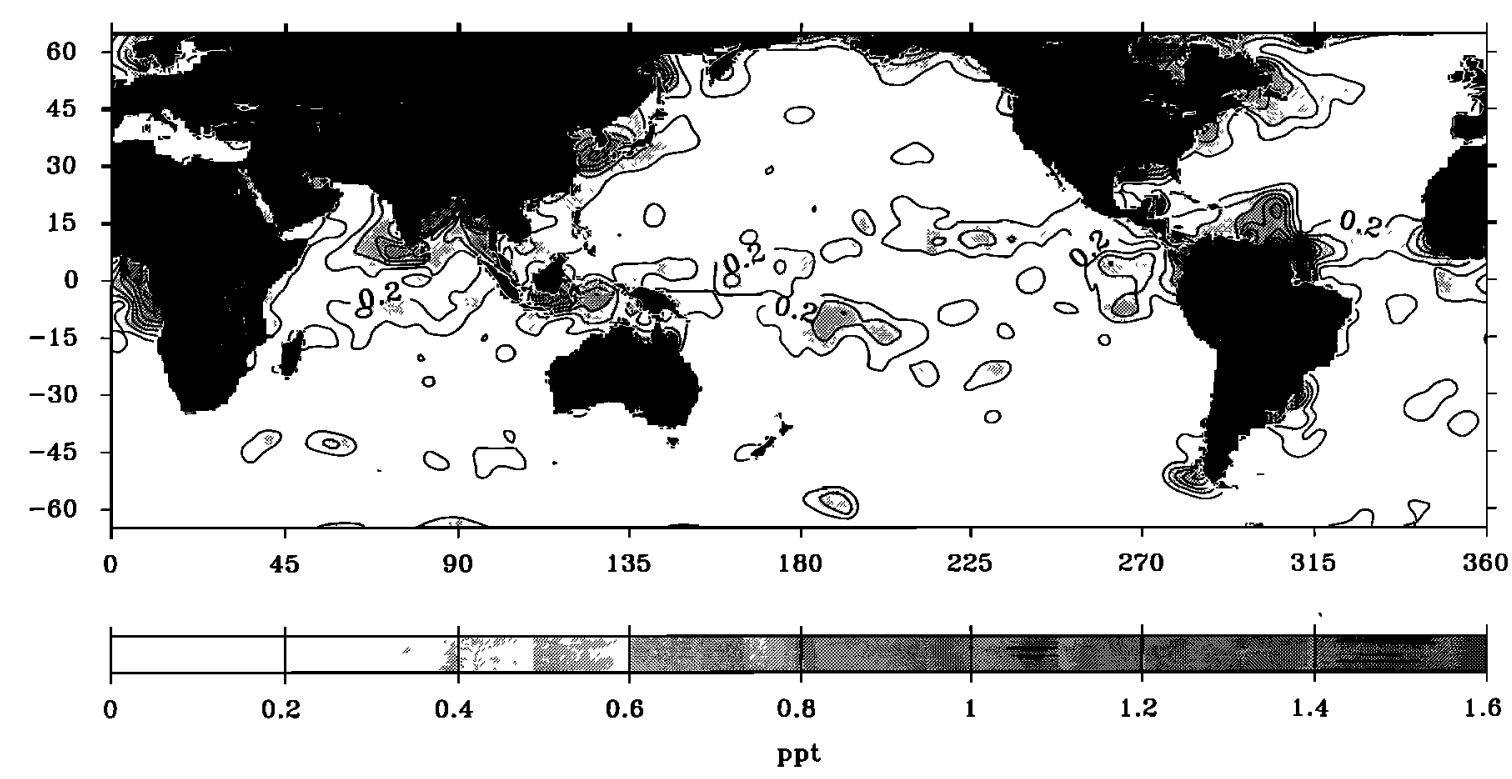

Figure 1. Amplitude of annual surface salinity variations from World Ocean Atlas 1994 [Levitus and Boyer, 1994]. 
where $\varepsilon$ is the error introduced by neglecting salinity and barotropic effects, as well as errors in the altimeter measurement. On the basis that Gill and Niiler's [1973] estimate of the size of the salinity and barotropic effects are accurate, and on the basis of the comparisons between TOPEX and tide gauge sea levels, we believe that the size of $E$ is at most 1 to $2 \mathrm{~cm}$ for the annual amplitude.

The other issue involving the use of (5) is the accuracy of the coefficients $\alpha, \rho$, and $c_{p}$. Over most of the ocean, the specific heat and density vary by less than $1 \%$, and so assuming that they are constant introduces little relative error. The largest error arises from the value used for $\alpha$, the thermal expansion coefficient. Because the thermal expansion coefficient is a function of the pressure level and temperature, it will vary with time and with depth. For this study, we will use surface values for the thermal expansion coefficient, based on monthly and annual mean temperature data. The value of the coefficient changes by about $250 \times 10^{-7} \mathrm{~K}^{-1}$ between the surface and $100 \mathrm{~m}$ depth, so we will assume an error in $\alpha$ of $250 \times 10^{-7} \mathrm{~K}^{-1}$. This will lead to large error estimates in colder waters (such as at high latitudes), where the surface value of $\alpha$ approaches the error.

The error in heat storage computed from (5) is

$$
\delta H=\frac{p c_{p}}{\alpha}\left(\delta \eta+\frac{\delta \alpha \Delta \eta}{\alpha}\right),
$$

where $\delta H$ is the error in heat storage, $\delta \alpha$ is the error in the thermal expansion coefficient, and $\delta \eta$ is the error in the sea level measurement. If we assume that the error in the annual sea level change, $\delta \eta$, is 0.01 to $0.02 \mathrm{~m}$, and we assume a value of $\rho=1027$ $\left(\mathrm{kg} \mathrm{m}^{-3}\right), c_{p}=4000 \mathrm{~J} \mathrm{~kg}^{-1} \mathrm{~K}^{-1}, \alpha=3000 \times 10^{-7} \mathrm{~K}^{-1}, \Delta \eta=0.06 \mathrm{~m}$, and $\delta \alpha=250 \times 10^{-7} \mathrm{~K}^{-1}$, the value of $\delta H$ is between 20 and $30 \mathrm{x}$ $10^{7} \mathrm{~J} \mathrm{~m}^{-2}$. This is equivalent to an error of 40 to $65 \mathrm{~W} \mathrm{~m}^{-2}$ in heat storage rate, roughly $50 \%$ larger than the error estimated for heat storage rates from temperature measurements. However, the satellite measurements will comprise a nearly global data set and may prove useful in supplementing heat storage measurements in areas where there are few or no temperature measurements.

This paper will examine the accuracy of using (5) to derive heat storage from TOPEX altimeter data. In particular, computations of the annual heat storage signal in the North Pacific and North Atlantic will be compared with previous studies to show agreement between the sea level method and the traditional temperature method. Interannual changes in the heat storage rate between 1992 and 1995 will be computed from the TOPEX data for the oceans between $65^{\circ} \mathrm{S}$ and $65^{\circ} \mathrm{N}$ and will be compared with long-period heat changes measured by the Tropical Ocean-Global Atmosphere program Tropical Atmosphere Ocean array (TOGA-TAO) and with long-term changes in sea surface temperature measured by the advanced very high resolution radiometer (AVHRR). The heat storage rates will be averaged over ocean basins to infer changes in the atmosphere-ocean heat flux over the same time period. Finally, quantitative errors in the long-term heat storage rate for each region of the globe will be assessed.

\section{Data Processing}

Sea level anomalies were computed from more than 3 years of 1-s rate TOPEX altimeter data available on the first release Geophysical Data Records (GDRs), from repeat cycle 5 to repeat cycle 132 (November 1992 to April 1996). All standard corrections were applied [Callahan, 1993], including the inverted barometer correction to remove atmospheric pressure effects, with the following exceptions: the GDR orbits have been replaced with those computed with the Joint Gravity Model (JGM-3) at the University of Texas Center for Space Research (UT/CSR), and the ocean tide model has been replaced with the
UT/CSR 3.0 model [Eanes and Bettadapur, 1995]. In addition, an error in the GDR data was discovered in July 1996 (D. Hancock and G. Hayne, personal communication, 1996). The source of the error is an improperly applied range correction to account for clock drift. If this were not fixed, there would be an erroneous 5 to $6 \mathrm{~mm} \mathrm{yr}^{-1}$ long-term drift in the altimeter measurement. This problem has been rectified in this analysis, using the correction supplied by D. Hancock and G. Hayne (personal communication, 1996). However, we have not applied the millimeter level range correction determined from an onboard calibration mode [Hayne et al., 1994], because TOPEX measurement show better long-term agreement with tide gauge sea levels when the calibration correction is not used (D. P. Chambers et al., manuscript in preparation, 1996; G. Mitchum, manuscript in preparation, 1996). The altimeter data were edited according to the flags set on the GDR and then further edited as described by Tapley et al. [1994].

The TOPEX altimeter does not repeat measurements at precisely the same point; observations are distributed within $a \pm 1$ $\mathrm{km}$ perpendicular to a nominal ground track, and at random points along the ground track. The $1-s$ rate and orbital speed means measurements are distributed more or less randomly along the ground track in bins $2 \mathrm{~km}$ wide and $6 \mathrm{~km}$ long. We have therefore computed sea level anomalies by interpolating the sea surface height to the center of these bins using a high-resolution mean sea surface (MSS) approximated by a plane. The parameters of the plane (along-track gradient, cross-track gradient, and mean height at the center) were estimated from the 3 years of TOPEX data, after removing any annual variability and editing any outliers. After the sea surface heights were interpolated to the center of the bin, sea level anomalies were computed by subtracting the mean height. All the data from any bin were edited if the along-track gradient of the MSS exceeded \pm 60 microradians, if less than 75 data points (about 2 years of data) were used to estimate the plane parameters, or if the water had a depth of less than $100 \mathrm{~m}$. This eliminated approximately $14 \%$ of the possible bins over the ocean, all in regions of seamounts, trenches, shallow oceans, and seasonal ice encroachment. Finally, the standard deviation of the sea level anomalies was computed in each bin, and if any particular sea level anomaly exceeded 3.5 times the standard deviation for the bin, it was edited.

The high-resolution sea level anomalies for each repeat cycle were then averaged into $1^{\circ}$ by $1^{\circ}$ equi-angle grids and smoothed in space by taking the weighted average of the $n$ valid data points in a rectangle about the center point, $h_{c}$, where

$$
\begin{aligned}
& h_{c}=\sum_{i=1}^{n} w_{i} \times h_{i} / \sum_{i=1}^{n} w_{i}, \\
& w_{i}=\exp \left[-\left(\frac{r}{5^{\circ}}\right)^{2}\right],
\end{aligned}
$$

and $r$ is the radius from $h_{c}$ to $h_{i}$.

The rectangle has the dimensions of $10^{\circ}$ in longitude and $4^{\circ}$ in latitude. It is not square because most ocean signals are coherent in longitude and not latitude, and a square filter aliases uncorrelated signals from one latitude to another. The filter effectively smoothes data over $1000 \mathrm{~km}$ in longitude and $450 \mathrm{~km}$ in latitude. The data were further smoothed in time over 30 days with a running-mean boxcar filter.

To determine the thermal expansion coefficient for each grid, we fit a third-order polynomial to $\alpha$ versus temperature, using data from Table A.3.1 of Gill [1982], assuming a constant salinity of $35 \mathrm{ppt}$ and surface pressures. Temperatures were determined from monthly and yearly averages in the World Ocean Atlas 1994 (WOA94) [Levitus and Boyer, 1994]. 


\section{Annual Heat Storage Anomalies}

Because of the concentration of XBT data in the northern hemisphere, most previous studies of heat storage have been limited to the North Pacific and Atlantic basins. Also, the studies have focused on mean annual signals and not interannual changes. Therefore we will begin by looking at the annual beat storage inferred from TOPEX sea level anomalies in these areas.

First, the sea level anomalies in each $1^{\circ}$ grid were converted into heat storage anomalies for each TOPEX repeat cycle using (5) with $p=1027 \mathrm{~kg} \mathrm{~m}^{-3}, c_{p}=4000 \mathrm{~J} \mathrm{~kg}^{-1} \mathrm{~K}^{-1}$, and monthly values of $\alpha$ determined for each grid. The heat storage anomalies were averaged over the Pacific and Atlantic basins from $20^{\circ}$ to $65^{\circ} \mathrm{N}$ and then smoothed with a 90-day wide running-mean boxcar filter to attenuate any high-frequency signals.

The heat storage anomalies for each $1^{\circ}$ grid were also computed using WOA94 temperature data and (1). Temperatures were integrated to the $8^{\circ} \mathrm{C}$ isotherm (or the isotherm closest to $8^{\circ} \mathrm{C}$, since levels are at standard depths) as suggested by Yan et al. [1995]. $\Delta T_{a}$ was computed as the difference between the monthly integrated temperature and the annual mean integrated temperature. These heat storage values were then averaged over the same areas of the North Pacific and Atlantic.

Figure 2 shows the heat storage anomalies computed with the TOPEX and the WOA94 data. The horizontal axis is time in
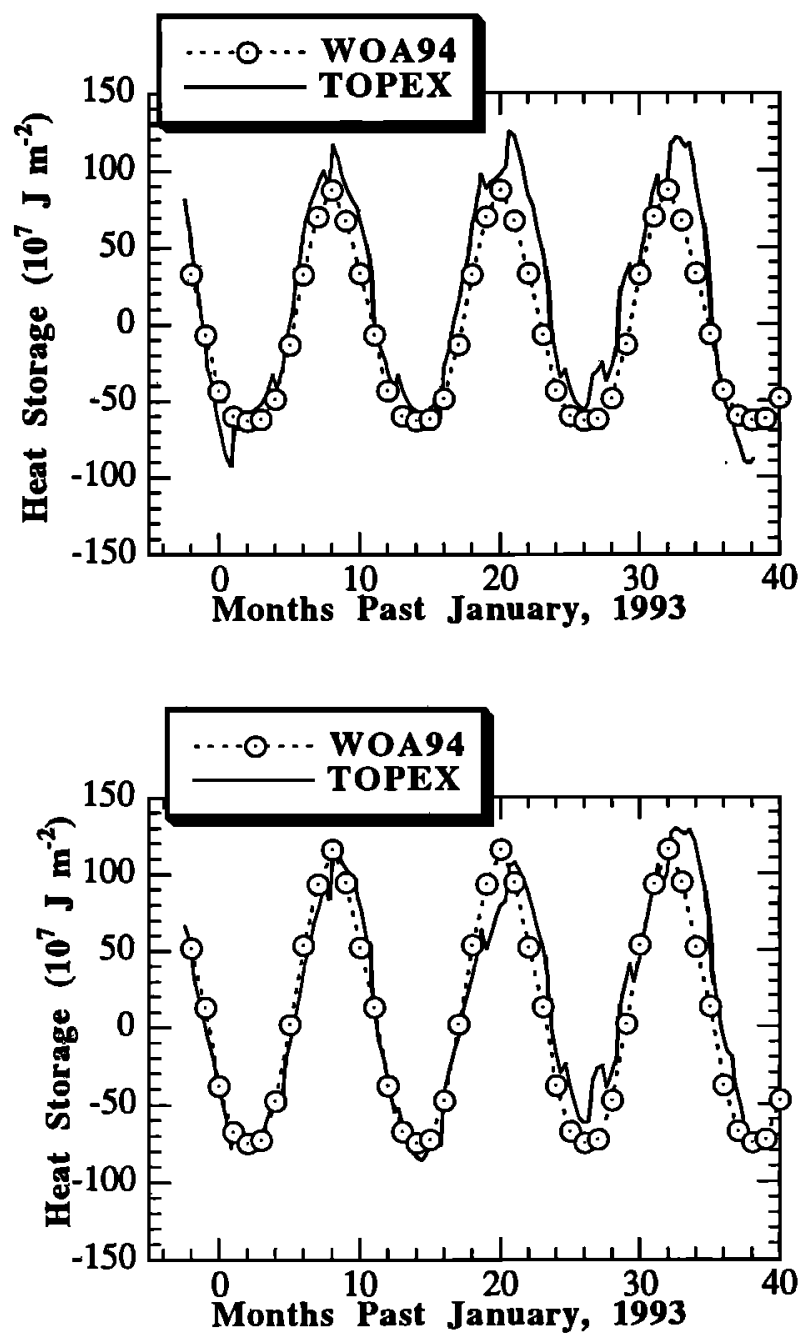

Figure 2. Seasonal heat storage anomalies(in $10^{7} \mathrm{~J} \mathrm{~m}^{-2}$ ) for (top) the North Pacific and (bottom) the North Atlantic. The solid line indicate TOPEX data; the open circles indicate monthly averaged WOA94 data.
Table 1. Amplitude of Annual Heat Storage Rates

\begin{tabular}{lcc}
\hline \multicolumn{1}{c}{ Study } & North Pacific & North Atlantic \\
\hline TOPEX, this study & 177 & 176 \\
WOA94, this study & 151 & 189 \\
Wyrtki and Uhrich [1982] & 163 & $\ldots$ \\
Yan et al. [1995] & 140 & $\ldots$ \\
Gill and Nuiler [1973] & $\ldots$ & 150 \\
Lamb and Bunker [1982] & $\ldots$ & 209 \\
\hline
\end{tabular}

Values are given in watts per square meter. Notes about data coverage: this study: entire basin, $20^{\circ} \mathrm{N}-65^{\circ} \mathrm{N}$ (WOA94 depth, $8^{\circ}$ isotherm); Wyrtki \& Uhrich [1982]: average between $30^{\circ}$ and $50^{\circ} \mathrm{N}$ at $158^{\circ} \mathrm{W}$ (depth, $100 \mathrm{~m}$ ); Yan et al. [1995]: averaged over six longitudes, $30^{\circ}-40^{\circ} \mathrm{N}$ (depth, $8^{\circ}$ isotherm); Gill \& Niiler [1973]: three stations in Atlantic (depth, 100-200 m); Lamb and Bunker [1982]: averaged over six latitude bands, $20^{\circ}-70^{\circ} \mathrm{N}$ (depth, $500 \mathrm{~m}$ )

months. The TOPEX data are real measurements from 1992 to 1996, sampled at a rate of three per month, and 0 represents January 1993. The WOA94 data are monthly means that are repeated every 12 months. The two data sets show very similar heat storage values, with nearly identical phases. The amplitude of the annual signal in the Pacific is $75.6 \times 10^{7} \mathrm{~J} \mathrm{~m}^{-2}$ for the WOA94 data and $88.8 \times 10^{7} \mathrm{~J} \mathrm{~m}^{-2}$ for the TOPEX measurements. In the Atlantic, the amplitudes are $94.9 \times 10^{7} \mathrm{~J} \mathrm{~m}^{-2}$ for WOA94 and $88.1 \times 10^{7} \mathrm{~J} \mathrm{~m}^{-2}$ for TOPEX. The difference in the amplitudes is between 6 and $13 \times 10^{7} \mathrm{~J} \mathrm{~m}^{-2}$, which is within the estimated error for heat storage anomalies computed from either the temperature or altimeter data.

By computing the annual amplitude of the heat storage rate from the derivative of the best fit curve, one can compare the values with those from previous studies (Table 1). The amplitudes agree well in both basins, with a standard deviation of $16 \mathrm{~W} \mathrm{~m}^{-2}$ in the Pacific and $25 \mathrm{~W} \mathrm{~m}^{-2}$ in the Atlantic. These differences are of the order of the error expected in the annual amplitude of heat storage rates from temperature data [Wyrtki and Uhrich, 1982].

All the studies agree in the phase of the annual signal, as well. The previous studies all show the maximum heat storage occurs in August to September, while the minimum occurs in January to February. The annual sinusoid fits to the TOPEX and WOA94 data have a maximum in September in both oceans and a minimum in January.

In the Pacific, the TOPEX data suggest lower than normal heat storage at the beginning of 1993 and 1996 (Figure 2) and slightly higher heat storage in the winter of 1994 and 1995. The TOPEX data in the Atlantic follow the WOA94 mean very well over the first 2 years and then show smaller heat losses and larger heat gains toward the end of 1994 (months 26 to 34). A similar, but smaller signal is also evident in the Pacific. However, it is impossible to say what the cause of the differences is using these data alone. The differences could be due to either changes in the surface beat flux or advection between 1992 and 1996, or to changes in salinity or barotropic effects that are not related to heating, or to a combination of all these effects. However, the overall agreement in the mean annual signal in both amplitude and phase is reassuring as to the use of (5) to compute heat storage anomalies from altimetric sea levels.

\section{Long-Term Heat Storage Rates}

To examine long-term beat storage changes, we compute the average heat storage rate for each $1^{\circ}$ grid of our sea level data for three periods: November 1992 to November 1994 (cycles 5-79), November 1992 to November 1995 (cycles 5-115), and November 1992 to April 1996 (cycles 5-132). A bias, linear trend (in time) and annual and semi-annual period sinusoids were 
fit to the data in each grid in a least squares sense. The estimated slope, $\Delta \eta / \Delta t$, was used to compute interannual heat storage rates $(\Delta H / \Delta t)$ for each grid by

$$
\frac{\Delta H}{\Delta t}=\frac{p c_{p}}{\alpha} \frac{\Delta \eta}{\Delta t},
$$

the time derivative of (5). The same constant values for density and specific heat were used as in the previous section, but a mean value of the thermal expansion coefficient was used in each grid.

At the same time, the error was estimated for each grid using (7), assuming that the error in $\alpha$ is $250 \times 10^{-7} \mathrm{~K}^{-1}$ and the error in the slope is $2 \mathrm{~cm} \mathrm{yr}^{-1}$. Although it is unknown how large the interannual changes in salinity and barotropic sea levels may be, we believe that this error estimate will bound them. The covariance matrix from the least squares solution suggests that the slope is well determined, with low correlations to other parameters and a standard deviation of $3 \mathrm{~mm} \mathrm{yr}^{-1}$ on average. Also, comparisons with tide gauge records in the Pacific suggest that the largest residual drift that may be present in the TOPEX altimeter is on the order of $3 \mathrm{~mm} \mathrm{yr}^{-1}$ (D. P. Chambers et al., manuscript in preparation, 1996). Thus, the errors in long-term sea level slope due only to the instrument and fit are on the order of $6 \mathrm{~mm} \mathrm{yr}^{-1}$.

Although interannual changes in the barotropic response are not well known, there is some documentation of long-term changes in salinity. Levitus [1989] showed that the surface salinity changed by as much as $\mathbf{0 . 5} \mathrm{ppt}$ in the North Atlantic between the late 1950 s and the early 1970 s, suggesting a mean rate of $0.03 \mathrm{ppt} \mathrm{yr}^{-1}$. Dessier and Donguy [1994] show a similar mean rate in the Atlantic for latitudes $25^{\circ}-30^{\circ} \mathrm{N}$ between 1977 and 1989. However, the rate for shorter time periods can be greater. Delcroix and Henin [1991] show rates of about 0.1 to $0.2 \mathrm{ppt} \mathrm{yr}^{-1}$ in the tropical Pacific over periods of 3 years. Again assuming a constant rate over $100 \mathrm{~m}$ depth, this corresponds to a sea level change of about 0.7 to $1.5 \mathrm{~cm} \mathrm{yr}^{-1}$. However, as Levitus [1989] indicates, the salinity changes at $100 \mathrm{~m}$ depth is generally smaller than the change at the surface, suggesting the overall salinity effect is less than $1.5 \mathrm{~cm} \mathrm{yr}^{-1}$ at most. This suggests that the $2 \mathrm{~cm} \mathrm{yr}^{-1}$ error should encompass both errors in the measurement and errors in not removing salinity and barotropic effects.

Plates 1 and 2 show the mean heat storage rates for each $1^{\circ}$ grid over 2 and 3 years, respectively, while Plate 3 shows the expected error. The rates for November 1992 to April 1996 are not shown, because they are very similar to the rates shown in Plate 2. Note that the expected error exceeds the heat storage rates at high latitudes. This is due mainly to the estimate of the accuracy of the thermal expansion coefficient, because at high latitudes the mean value is the same size as our assumed error. Although the true error at high latitudes is probably less than what is shown in Figure 5, we have no way to verify this. The mean of the errors shown in Plate 3 is $14 \mathrm{~W} \mathrm{~m}^{-2}$.

However, this value is dominated by the large values at high latitudes. Between $45^{\circ} \mathrm{S}$ and $45^{\circ} \mathrm{N}$, the mean is $9.7 \mathrm{~W} \mathrm{~m}^{-2}$. This error is also largely due to the assumed slope error. If we assume a slope error of only $1 \mathrm{~cm} \mathrm{yr}^{-1}$, implying non-heating-related sea level changes of up to $5 \mathrm{~mm} \mathrm{yr}^{-1}$, the estimated error would drop by a factor of 2 . Thus we estimate that the error in the longperiod heat storage rates computed over a $1^{\circ}$ by $1^{\circ}$ region from the TOPEX sea level data is between 5 and $10 \mathrm{~W} \mathrm{~m}^{-2}$.

To verify our results, we turn to a measurement of heat storage made during the same time as the TOPEX data that has a similar basin-wide scale: the TOGA-TAO array in the tropical Pacific [McPhaden, 1993]. Conveniently, this array is situated in the area of the largest heat changes in the ocean, the warm pool in the western Pacific and the area east of $225^{\circ} \mathrm{E}$ on the equator extending to Peru.

Using maps of monthly-averaged heat content to $300 \mathrm{~m}$ computed from the TOGA-TAO measurements provided on the
Table 2. Interannual Heat Storage Rate Comparisons, TOPEX and TOGA-TAO

\begin{tabular}{|c|c|c|c|c|}
\hline \multirow[b]{2}{*}{ Location } & \multicolumn{2}{|c|}{ Nov. 1992 to Nov. 1994} & \multicolumn{2}{|c|}{ Nov. 1992 to Nov. 1995} \\
\hline & TOPEX & TAO & TOPEX & TAO \\
\hline $\begin{array}{l}-4.5^{\circ} \mathrm{S}, \\
165^{\circ} \mathrm{E}\end{array}$ & 30 & 40 & 20 & 33 \\
\hline $\begin{array}{r}0^{\circ}, \\
220^{\circ} \mathrm{E}\end{array}$ & -5 & 6 & -9 & -1 \\
\hline $\begin{array}{r}0^{\circ}, \\
250^{\circ} \mathrm{E}\end{array}$ & -11 & -10 & -8 & -13 \\
\hline
\end{tabular}

Values are given in watts per square meter.

internet by the National Oceanic and Atmospheric Administration (NOAA) Pacific Marine Environmental Laboratory, we have estimated the long-term heat storage rates at three sites over the same span as used for the TOPEX results (Table 2). The agreement is at the level of $10 \mathrm{~W} \mathrm{~m}^{-2}$ in the warm pool, while the agreement in the eastern part of the basin is about $5 \mathrm{~W} \mathrm{~m}^{-2}$. These results agree very well with the estimated errors shown in Plate 3. Although this is not a large sample of comparisons, it suggests that the errors indicated in Plate 3 are accurate.

Returning to the heat storage rates shown in Plate 1 , we note the large heating increase in the western Pacific in the warm pool, as well as the cooling in the eastern Pacific between 1993 and 1994. These patterns are associated with the El Niño event which began near the end of 1992 and ended in 1993. A similar pattern is also present in the Indian Ocean. It is most likely tied to the change in wind forcing associated with El Niño events. The large negative heat storage rates west of Sumatra in Plate 1 are indicative of increased upwelling due to stronger Trade winds as the atmosphere adjusts back to normal conditions. The large change in the south-central Indian Ocean is also connected to the wind change, but in the form of annual Rossby waves.

Perigaud and Delecluse [1992], using a numerical model, have shown that annual period Rossby waves are a normal mode in this part of the Indian Ocean, due to seasonal wind forcing. A time-longitude plot of sea levels measured by TOPEX/POSEIDON show these annual period Rossby waves at latitude $13^{\circ} \mathrm{S}$ (Figure 3). Although there were strong upwelling waves (indicated by negative sea level anomalies) across the basin from 1992 to 1994, the downwelling wave (indicated by positive sea level anomalies) that started in November 1992 near longitude $90^{\circ} \mathrm{E}$ did not travel much farther west than $80^{\circ} \mathrm{E}$. However, the downwelling wave the next year travels across the basin. Thus, between $50^{\circ}$ and $80^{\circ} \mathrm{E}$, there is a large positive gain in heat from 1992 to 1994, due to the lack of a downwelling Rossby wave in 1992-1993, and the presence of one in 19941995. The disappearance of the downwelling wave in February 1993 correlates with the start of the 1992-1993 El Niño event in the Pacific [McPhaden, 1993], while the stronger downwelling wave the next year correlates with the return to normal wind forcing.

The effect of another Rossby wave is also seen in Plate 1 , in the northwestern Pacific. The band of positive heat storage rates stretching from northwest of Hawaii to the Philippines near $15^{\circ} \mathrm{N}$ is caused by the passage of a low-frequency Rossby wave between 1992 and 1994 [Jacobs et al., 1994]. Other large changes in local heat storage rates from 1992 to 1994 occur in the major currents: the Gulf Stream, the Kuroshio extension, the Aghulas, the Antarctic Circumpolar Current, and the Brazil/Falkland confluence.

Plate 2, which shows the heat storage rates averaged over 3 years, shows some of the features in Plate 1 , but at reduced 


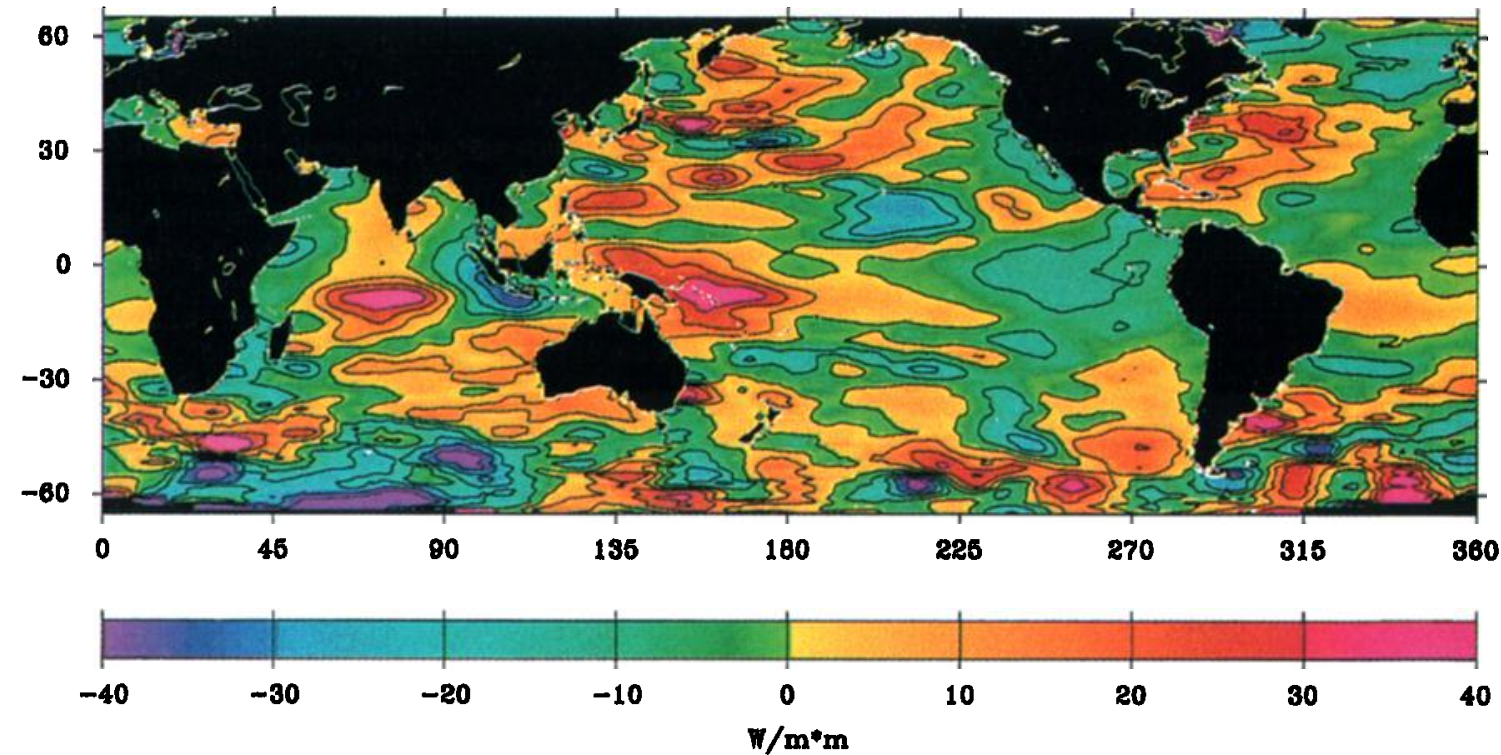

Plate 1. Interannual beat storage rates inferred from TOPEX sea level change over the period November 1992 to November 1994 (cycles 5-79).

levels. The large change in the warm pool is still evident, as is the large signal in the Indian Ocean due to the Rossby wave. More interesting in terms of long-term climate change are the mean differences over basins. For example, the Atlantic Ocean north of the equator shows mostly positive heat storage rates, while the Pacific shows mostly positive rates south of the equator and to the northwest but mostly negative heat storage rates north and east of the equator.

One would like to verify the results, in order to assess the level of the error. Unfortunately, direct heat storage rate measurements at this resolution are not available globally. However, changes in heating will cause changes in ocean temperatures, including the sea surface temperature (SST), and global measurements of SST are available over the period studied here. We have used the weekly averaged SSTs from the NOAA AVHRR, available via the internet from the Physical Oceanography Distributed Active Archive Center (PODAAC) housed at the Jet Propulsion Laboratory (JPL). The highresolution data have been averaged into the same $1^{\circ} \mathrm{grid}$ used with the TOPEX data, and then a linear trend, along with annual and semi-annual sinusoids, was estimated for each grid using the weekly data from October 1992 to October 1995. The slopes of the linear trend (in degrees Celsius per year) are shown in Plate 4.

Ignoring the different units, we note that the qualitative agreement between Plates 4 and 2 (TOPEX heat rates over the same time) is very good. In general, there are positive SST rates in the same areas as positive heating rates. Negative SST rates and heating rates are also well correlated. Even areas with extreme rates agree. We note that the large SST rates in the northeastern Atlantic, east of New Zealand, in the Kuroshio extension, and northwest of Hawaii are all coincident with heat storage rates which are in excess of $10 \mathrm{~W} \mathrm{~m}^{-2}$. The SST data also indicate that most of the Atlantic ocean north of the equator increased in temperature from late 1992 to late 1995. The

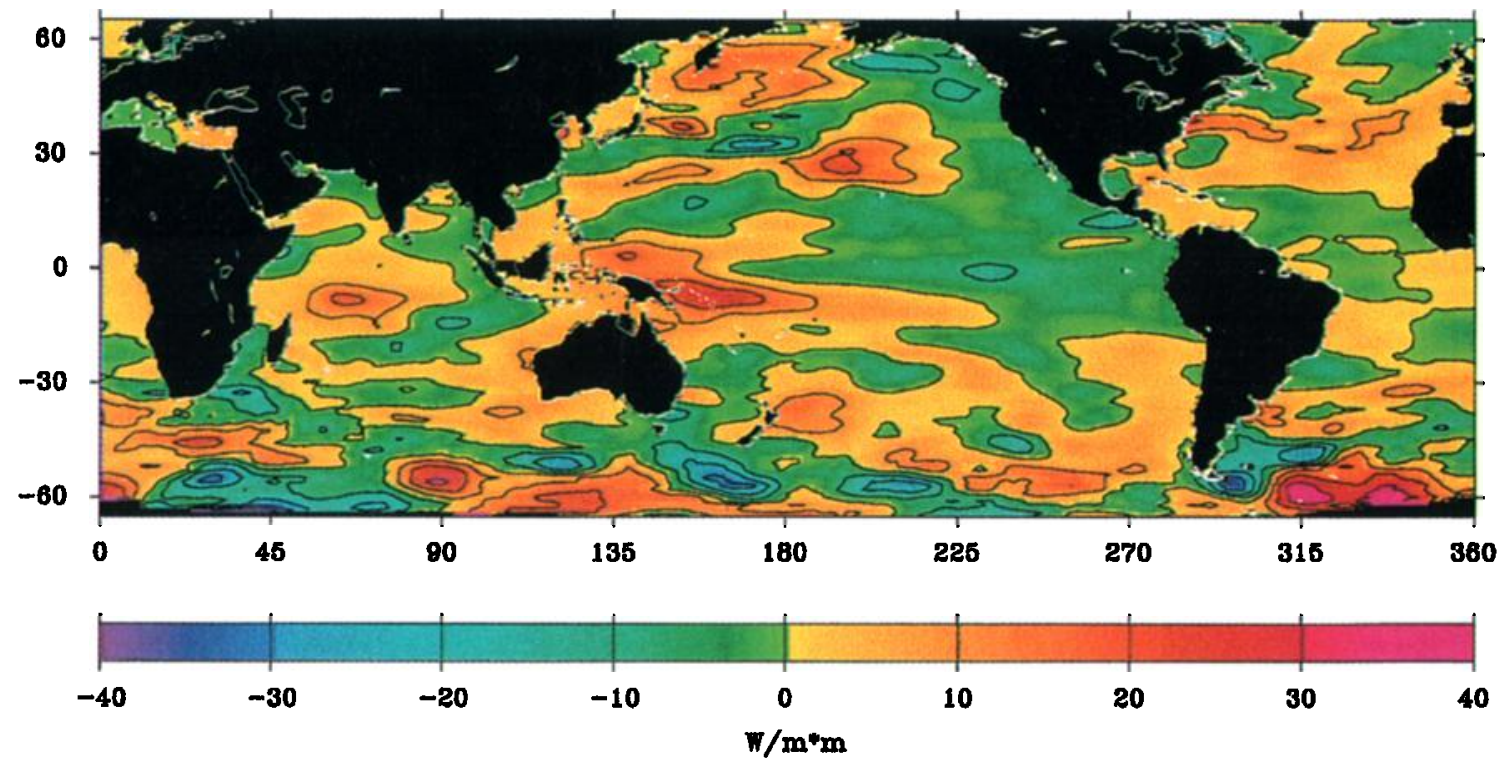

Plate 2. Interannual heat storage rates inferred from TOPEX sea level change over the period November 1992 to November 1995 (cycles 5-115). 


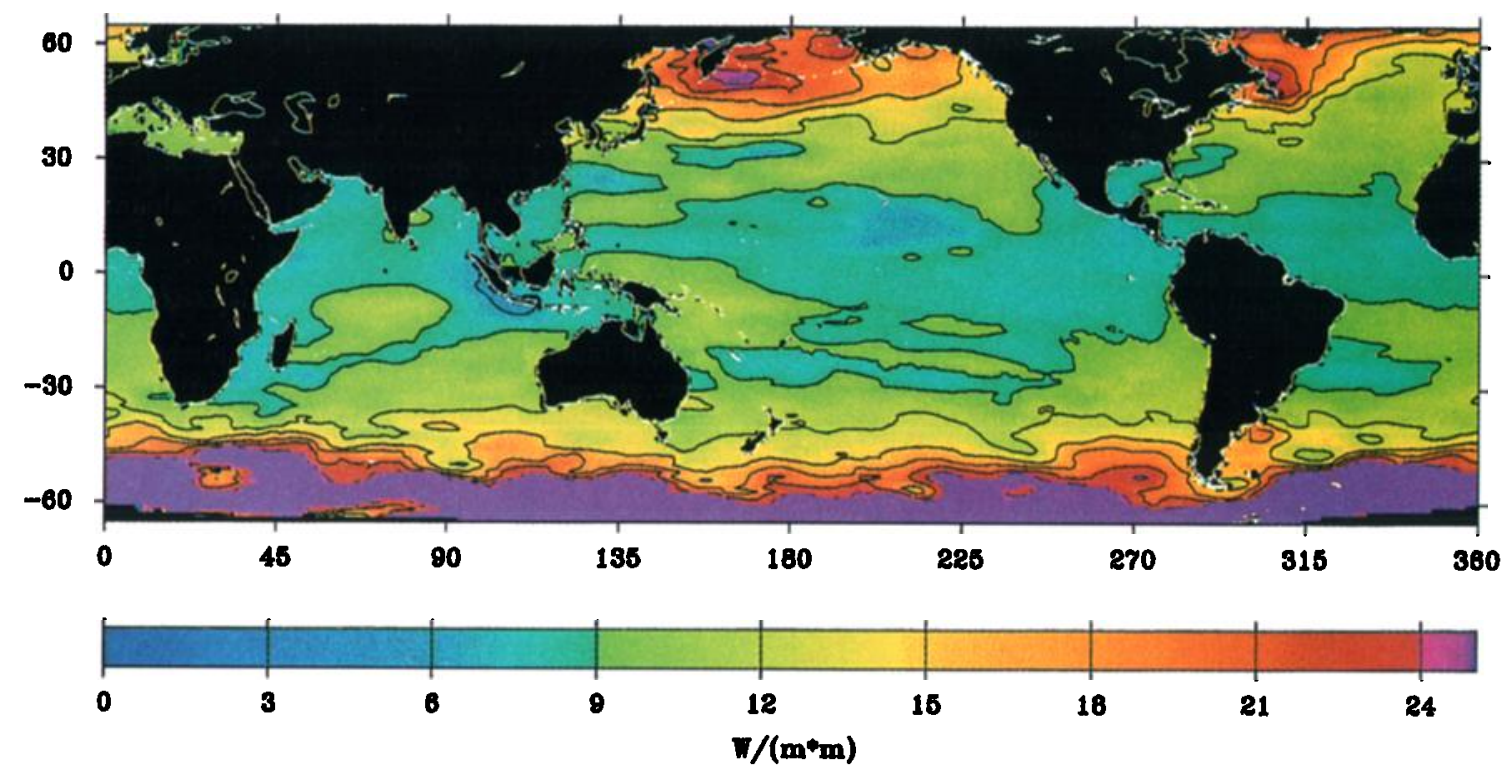

Plate 3. Estimated error in interannual heat storage rates inferred from TOPEX sea level change.

alternating positive and negative heat storage and SST rates in the far southern hemisphere are associated with the variability of the Antarctic Circumpolar Wave [Jacobs and Mitchell, 1996].

\section{Basin-Scale Atmosphere-Ocean Heat Fluxes}

Although these beating and cooling patterns around the globe are intriguing, it is difficult to determine whether they are caused by changes in advection or heat flux from the atmosphere, since the rate of heat storage is the sum of the heat flux and advection and diffusion terms. However, most of the advection term is due to heat carried by the large-scale ocean circulation, and diffusion is small and slow. If the heat storage rates determined from altimetry are integrated over an entire ocean gyre, then the advection should sum to a small value. Provided that there are no systematic errors in the altimeter measurement and that salinity and barotropic sea level effects also average to a small value, then the integral should, to first order, represent the mean heat flux across the atmosphere-ocean interface in the basin.

To study this, the heat storage rates are integrated over the North Pacific $\left(0^{\circ}-65^{\circ} \mathrm{N}\right)$, the North Atlantic $\left(0^{\circ}-65^{\circ} \mathrm{N}\right.$, including the Mediterranean Sea and the Gulf of Mexico), the southern hemisphere $\left(65^{\circ} \mathrm{S}-0^{\circ}\right)$, and the global ocean $\left(65^{\circ} \mathrm{S}\right.$ $65^{\circ} \mathrm{N}$ ) as

$$
Q=\frac{\sum_{i=1}^{N}\left(\frac{\Delta H}{\Delta t}\right) d A}{A},
$$

where $Q$ is the mean heat storage rate for the basin (watts per square meter), $N$ is the number of grids in the basin, $A$ is the area of the basin (computed as the sum of $d A$ ), $d A=\cos$ (latitude) $\mathrm{x}$ $(111319 \mathrm{~m})^{2}$ (the area of each $1^{\circ}$ grid). The integral is taken over the entire southern hemisphere because the Antarctic

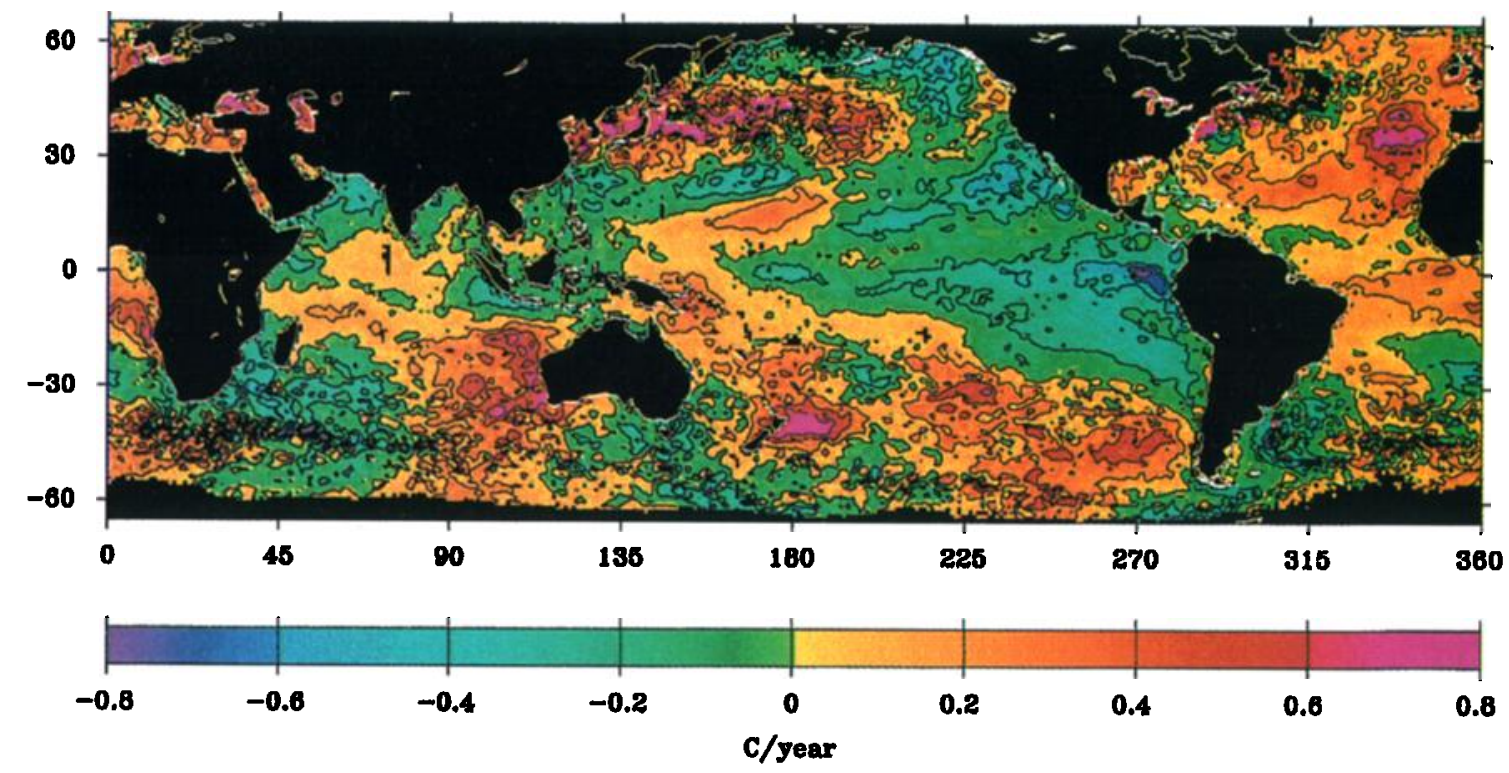

Plate 4. Interannual sea surface temperature rates determined from AVHRR SST data over the period October 1992 to October 1995. 
Circumpolar Current (ACC) flows through the southern Indian, Pacific, and Atlantic Oceans and has large transports. Thus, to ensure the advection term is small, the data are averaged over the entire area of the ACC.

We will assume that the mean long-term sea level changes due to salinity changes and barotropic response are small compared to mean errors in the altimeter measurement. As noted previously, comparisons with tide gauge data suggest an agreement between TOPEX and gauge long-term sea level change of the order of 2 to $3 \mathrm{~mm} \mathrm{yr}^{-1}$. If we assume that this difference is due completely to altimeter error, then this will correspond to an average heat flux error of approximately 1 to $1.5 \mathrm{~W} \mathrm{~m}^{-2}$, comparable to the error in basin-scale heat storage rates suggested by White and Tai [1995].

Table 3 lists the value of $Q$ computed from the TOPEX measurements. Note that the heat fluxes computed over the first 2 years of the mission are much smaller than the expected error, and so are not considered significantly different than zero. For the 3 year and $31 / 2$ year periods, however, the fluxes are larger in every basin except the North Pacific. The North Pacific still has effectively zero flux. The average stored heat in the North Atlantic and southern hemisphere appears to have increased to about 1.5 to $2 \mathrm{~W} \mathrm{~m}^{-2}$ from November, 1992 to April, 1996, suggesting a net increase in mean heat flux of the same amount into the oceans from the atmosphere. Averaged globally, the mean rate appears to be 1 to $1.5 \mathrm{~W} \mathrm{~m}^{-2}$. However, these values
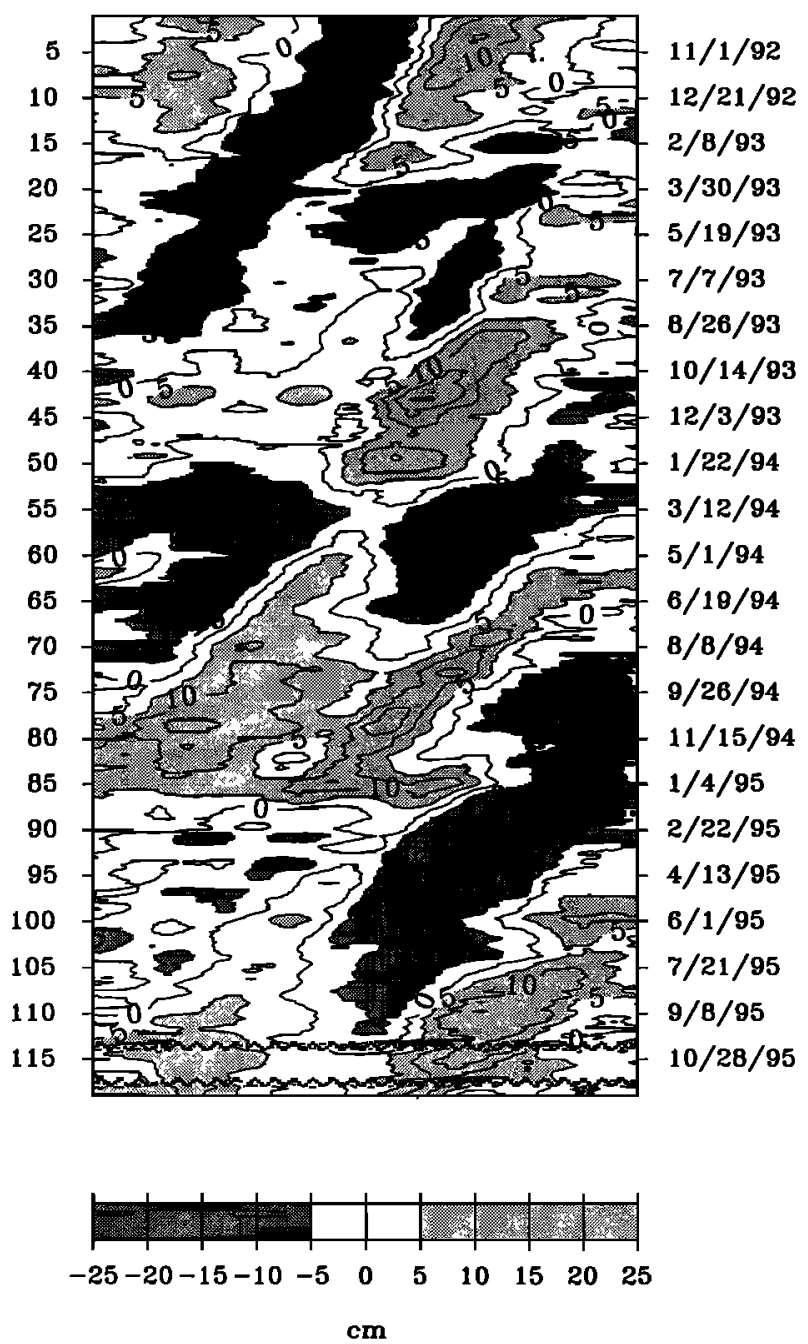

Figure 3. Time-longitude plot of TOPEX sea level anomalies in Indian Ocean, smoothed over 90 days in time. The left vertical axis is the TOPEX/POSEIDON repeat cycle, while the right vertical axis is the calendar date.
Table 3. Basin-Scale Atmosphere-Ocean Heat Fluxes

\begin{tabular}{lcccc}
\hline & \multicolumn{2}{c}{ TOPEX } & & AVHRR \\
\cline { 2 - 3 } & $\begin{array}{c}\text { Nov. 1992 to } \\
\text { Nov. 1994 }\end{array}$ & $\begin{array}{c}\text { Nov. 1992 to } \\
\text { Nov. 1995 }\end{array}$ & $\begin{array}{c}\text { Nov. 1992 to } \\
\text { Nov. 1995 }\end{array}$ \\
\hline $\begin{array}{l}\text { North } \\
\text { Pacific }\end{array}$ & 0.4 & 0.2 & -0.1 \\
$\begin{array}{l}\text { North } \\
\text { Atlantic }\end{array}$ & -0.9 & 1.5 & 1.9 \\
$\begin{array}{l}\text { Southern } \\
\text { hemisphere }\end{array}$ & 0.2 & 1.4 & 2.3 \\
$\begin{array}{l}\text { Global } \\
\text { ocean }\end{array}$ & 0.0 & 1.1 & 1.6 \\
\hline
\end{tabular}

Values are given in watts per square meter.

are not significantly larger than the expected error. If the error is positive, then the mean global flux is effectively zero. If the error is negative, then the estimated global flux is 2 to $3 \mathrm{~W} \mathrm{~m}^{-2}$.

We turn again to the SST data (Plate 4) to see if they support these results. Unfortunately, as discussed previously, one cannot compute heat storage rates from temperature data without assuming a reference level. Using SST data, one also has to assume that the temperature change seen at the surface is present throughout the upper layer, which is not necessarily true. However, to estimate a mean heat storage rate from the SST data, we will make the latter assumption as well as assume that the upper layer depth is a fixed $100 \mathrm{~m}$. With these assumptions, the SST slopes, integrated over the basins in the same manner as the TOPEX data, imply mean heat storage rates of $-0.5 \mathrm{~W} \mathrm{~m}^{-2}$ in the north Pacific, $2.6 \mathrm{~W} \mathrm{~m}^{-2}$ in the north Atlantic, and $0.5 \mathrm{~W} \mathrm{~m}^{-2}$ in the southern hemisphere and globally. These results agree with the values obtained from the TOPEX sea level measurements to within $1.5 \mathrm{~W} \mathrm{~m}^{-2}$, the expected error. More importantly, both data sets indicate that the North Atlantic has warmed at a higher rate per unit area than the North Pacific between 1993 and 1995.

\section{Conclusions}

Using a linear relation between heat storage and sea level anomalies, we have shown that the heat storage values calculated from TOPEX altimetry agree well with those computed from temperature data in the mean annual amplitude and phase. We have also demonstrated that interannual heat storage rates computed from the TOPEX data agree well with similar rates computed from the TOGA-TAO measurements in the tropical Pacific, of the order of 5 to $10 \mathrm{~W} \mathrm{~m}^{-2}$. The regional heat storage rates computed from the TOPEX data also correlate very well with interannual sea surface temperature changes. Both data sets show similar patterns of heating and cooling, as well as similar locations for extremes.

Finally, we have used average heat storage rates over basins to infer changes in the mean heat flux between the atmosphere and the ocean. Both FOPEX and the SST data indicate that the North Atlantic warmed at a significantly higher rate per unit area than any other basin, while the northern Pacific either lost heat to the atmosphere or maintained a near zero flux on average. Given the time span of TOPEX data available and the remaining uncertainty in millimeter level drifts which may be present in the measurements, we can only bound the flux to between 0 and $3 \mathrm{~W}$ $\mathrm{m}^{-2}$. However, because the SST measurements have shown significant increases over the same time in the same regions, we suspect that the real value is positive, suggesting heating from the atmosphere into. the oceans over much of the globe, except in the northern Pacific.

Acknowledgments. The authors would like to thank David Hancock and George Hayne at NASA Wallops Space Flight Center for providing the 
proper corrections to the altimeter range due to the clock drift, Michael McPhaden at NOAA PMEL for maintaining the TOGA-TAO web site, and the JPL PODAAC for providing the AVHRR data. We would also like to acknowledge the comments and suggestions of one of the anonymous reviewers which helped us improve this paper. We would further like to thank R. Steven Nerem at CSR for useful discussions on this topic. This research was supported by the TOPEX/POSEIDON Project at the NASA Jet Propulsion Laboratory under contract JPL 958122.

\section{References}

Callahan, P. S., TOPEX/POSEIDON NASA GDR Users Handbook, JPL Rep. D-8590, Rev. C, Jet Propul. Lab., Pasadena, Calif., 1993.

Cheney, R., L. Miller, R. Agreen, N. Doyle and J. Lillibridge, TOPEX/POSEIDON: The 2-cm solution, J. Geophys. Res., 99(C12), 24,555-24,563, 1994

Delcroix, T., and C. Henin, Seasonal and interannual variations of sea surface salinity in the tropical Pacific Ocean, J. Geophys. Res. 96(C12), 22,135-22,150, 1991.

Dessier, A., and J. R. Donguy, The sea surface salinity in the tropical Atlantic between $10^{\circ} \mathrm{S}$ and $30^{\circ} \mathrm{N}$-- Seasonal and interannual variations (1977-1989), Deep Sea Res., Pant 1, 41, 81-100, 1994.

Eanes, R., and S. Bettadapur, The CSR 3.0 global ocean tide model, CSRTM-95-06, Cent. for Space Res., Univ. of Tex., Austin, 1995.

Esbensen, S. K., and Y. Kushnir, Heat Budget of the Global Ocean, Clim. Res. Inst. Rep. 29, Oreg. State Univ., Corvallis, 1981.

Fu, L. L., and R. A. Davidson, A note on barotropic response of sea level to time-dependent wind forcing, J. Geophys. Res., $100(\mathrm{C12}), 24,955$ $24,963,1995$.

Gill, A. E., Atmosphere-Ocean Dynamics, Academic, San Diego, Calif., 1982.

Gill, A. E., and P. P. Niiler, The theory of seasonal variability in the ocean, Deep Sea Res., 20, 141-177, 1973.

Hayne, G. S., D. W. Hancock, and C. L. Purdy, TOPEX alumeter range stability estumated from calibration mode data, TOPEX/POSEIDON Res. News, JPL 410-42, 3, pp. 18-22, Jet Propul. Lab., Pasadena, Calif., 1994.

Jacobs, G. A., and J. L. Mitchell, Ocean circulation variations associated with the Antarctic Circumpolar Wave, Geophys. Res. Lett.., 23, 2947. $2950,1996$.

Jacobs, G. A., H. E. Hurlburt, J. C. Kindle, E. J. Metzger, J. L. Mitchell, W. J. Teague, and A J. Wallcraft, Decadal-scale trans-Pacific propagation and warming effects of an El Niño anomaly, Nature, 370, 360-363, 1994.

Lamb, P. J. and A. F. Bunker, The annual march of the heat budget of the North and tropical Atlantic Ocean, J. Phys. Oceanogr., 12, 1388-1410, 1982.

Levitus, S., Interpentadal variability of salinity in the upper $150 \mathrm{~m}$ of the North Atlantic Ocean, 1970-1974, versus 1955-1959, J. Geophys. Res., 94(C7), 9679-9685, 1989.

Levitus, S., and T. P. Boyer, World Ocean Atlas 1994 vol. 4 Temperature, NOAA Atlas NESDIS 4, 117 p., Natl. Oceanic and Atmos. Admin., Silver Spring, Md., 1994.

McPhaden, M. J., TOGA-TAO and the 1991-93 El Niño-Southern Oscillation event, Oceanography, 6(2), 36-44, 1993.

Mitchum, G., Comparison of TOPEX sea surface heights and tide gauge sea level, J. Geophys. Res., 99(C12), 24,541-24,554, 1994.

Perigaud, C., and P. Delecluse, Annual sea level variations in the southern tropical Indian Ocean from Geosat and shallow-water simulations, J. Geophys. Res., 97(C12), 20,169-20,178, 1992.

Repert, J. P., J. R. Donguy, G. Elden, and K. Wyrtki, Relations between sea level, thermocline depth, heat content, and dynamic height in the tropical Pacific Ocean, J. Geophys. Res., 90(C6), 11,719-11,725, 1985.

Stevenson, J. W., and P. P. Niiler, Upper ocean heat budget during the Hawaii-to-Tahiti shuttle experiment, J. Phys. Oceanogr., 13, 1894 $1907,1983$.

Tapley, B. D., D. P. Chambers, C. K. Shum, R. J. Eanes, J. C. Ries, and R. H. Stewert, Accuracy assessment of the large-scale dynamic ocean topography from TOPEX/POSEIDON altimetry, J. Geophys. Res. 99(C12), 24,605-24,618, 1994.

White, W. B., and C. K. Tai, Inferring interannual changes in global upper ocean heat storage from TOPEX altimetry, J. Geophys. Res. loO(Cl2), 24,943-24,954, 1995

Wyrtki, K., and L. Uhrich, On the accuracy of heat storage computations, J. Phys. Oceanogr.., 12, 1412-1416, 1982.

Yan, X. H., P. P. Niiler, S. K. Nadiga, R. H. Stewart, and D. R. Cayan, Seasonal heat storage in the North Pacific: 1976-1989, J. Geophys. Res., 100(C4), 6899-6926, 1995.

D. P. Chambers and B. D. Tapley, Center for Space Research, University of Texas, 3925 W. Braker Lane, Suite 200, Ausun, TX 787595321. (e-mail: chambers@csr.utexas.edu)

R. H. Stewart, Department of Oceanography, Texas A \& M University, College Station, TX 77840

(Received April 12, 1996; revised October 29, 1996; accepted November 8, 1996.) 